\title{
Successful closure of an empyema space associated with persistent bronchopleural fistula: Muscle transposition combined with endobronchial plug
}

\author{
Hisashi Oishi, MD, Akira Miyamoto, MD, Akira Sakuraada, MD, Yasushi Hoshikawa, MD, Hirokazu Aikawa, MD, \\ Satoshi Suzuki, MD, Masami Sato, MD, and Takashi Kondo, MD, Sendai, Japan
}

$\mathrm{E}$ mpyema associated with bronchopleural fistula (BPF) is one of the serious complications after pulmonary resection. ${ }^{1}$ Various methods (eg, direct suture of BPF, omental and muscular transposition, thoracoplasty, or a combination of them) have been indicated to treat empyema. However, these treatments often fail because of the recurrent BPFs. ${ }^{1-4}$ In these treatments, complete obliteration of residual pleural space is important to prevent the recurrence of BPF.

Here we report a successful treatment for a patient with persistent BPF. The patient was lean and did not have enough muscles for pleural space obliteration, so we devised a new methodmuscle transposition combined with an endobronchial plug.

\section{Clinical Summary}

A 70-year-old man was admitted to our hospital because of empyema associated with BPF. Eleven months before admission, the patient underwent right upper lobectomy and right S6 partial resection for a lung nodule at another hospital. The pathologic diagnosis was pulmonary amyloidosis. Two months later, intrathoracic muscular transposition (latissimus dorsi muscle) and omentopexy were performed for BPF after the pulmonary resection. A month after the muscular transposition, BPF recurred, necessitating closed tube drainage thereafter. Bronchoscopic examination on admission revealed that the bronchial stump at the right B6a was open to the pleural cavity. We embolized the bronchus with a silicone plug. Air leakage stopped and the pleural space was successfully and safely irrigated with $0.1 \%$ povidone-iodine solution. However, the plug migrated from the causative bronchus to the pleural space, and subsequent attempts to close the BPF through endobronchial procedures (eg, embolization by coil for vascular or fibrin glue) were all unsuccessful. Seven months after admission, open window thoracostomy was performed and the dressing of the thoracostomy was changed twice a day, resulting in successful clearance.

From the Department of Thoracic Surgery, Institute of Development, Aging and Cancer, Tohoku University, Sendai, Japan.

Received for publication June 21, 2004; revisions received July 22, 2004; accepted for publication July 28, 2004.

Address for reprints: Hisashi Oishi, Department of Thoracic Surgery, Institute of Development, Aging and Cancer, Tohoku University, 4-1 Seiryo-machi, Aoba-ku Sendai 980-8575, Japan (E-mail bigstone@ idac.tohoku.ac.jp).

J Thorac Cardiovasc Surg 2005;129:692-3

$0022-5223 / \$ 30.00$

Copyright $\odot 2005$ by The American Association for Thoracic Surgery

doi:10.1016/j.jtcvs.2004.07.049
The patient's height was $160 \mathrm{~cm}$ and his body weight was 44 $\mathrm{kg}$. We considered that it was difficult to obliterate the space by conventional methods because of muscle deficiency and persistent BPF. We therefore planned to apply a novel technique that was reported by Watanabe and associates. ${ }^{2}$ We fully informed the patient about this method and obtained his consent. We made a plug with a stainless steel wire (Figure 1) from vinyl polysiloxane impression material (Exabite II, GC America, Inc, Alsip, Ill). Then the plug was wedged into the causative bronchus and muscle flap transposition was performed in the following steps: (1) the patient was intubated under general anesthesia with an endotrachial tube, into which the flexible bronchoscope was passed; (2) the guide wire was pulled from the pleural cavity to the outside of the endotracheal tube; (3) the guide wire and the plug's wire were tied, and then the plug was drawn into the causative bronchus and wedged there; (4) the flap of trapezium muscle was prepared and the edge of the flap was sutured with the plug's wire; then muscle flap transposition was performed (Figure 2); (5) obliteration of the pleural space and of air leakage around the plug was ensured, and a catherter was inserted beneath the incision for suction drainage.

The postoperative course was uneventful, and the patient was discharged on the 26th postoperative day. At 1 year's follow up, the patient had no recurrence of empyema.

\section{Discussion}

After open window thoracostomy for empyema, the closure of residual pleural space is technically a challenge for thoracic surgeons. ${ }^{1}$ If empyema recurs, immediate open window thoracostomy is required. In this case, we did not apply usual means because of persistent BPF over 9 months and insufficient muscular flaps.

We treated this patient with the novel technique reported by Watanabe and associates ${ }^{2}$ and successfully controlled the BPF. After the operation the plug stayed in the causative bronchus and no air leakage was observed. It is necessary to buttress the muscle flap to avoid a recurrent BPF. ${ }^{2}$ Muscle flaps without enough volume cannot maintain the buttressing. In this case, the plug's wire helps the plug the remain wedged in the causative bronchus and helps to buttress the muscle flap. We believe the muscular transposition is more effective with the unique plug and wire than without them.

We made the plug from impression material for dentistry. We have no plan to extract it from the patient's bronchus, because the patient does not have infection around the plug. As Watanabe and colleagues ${ }^{2}$ described, "The ingredients of this material have no toxicity to the human body. However, the manufacture does not yet extend any guarantee concerning this material for this surgery." Therefore, we must follow up this patient especially with regard to the plug by bronchoscopy and computed tomographic scanning. 


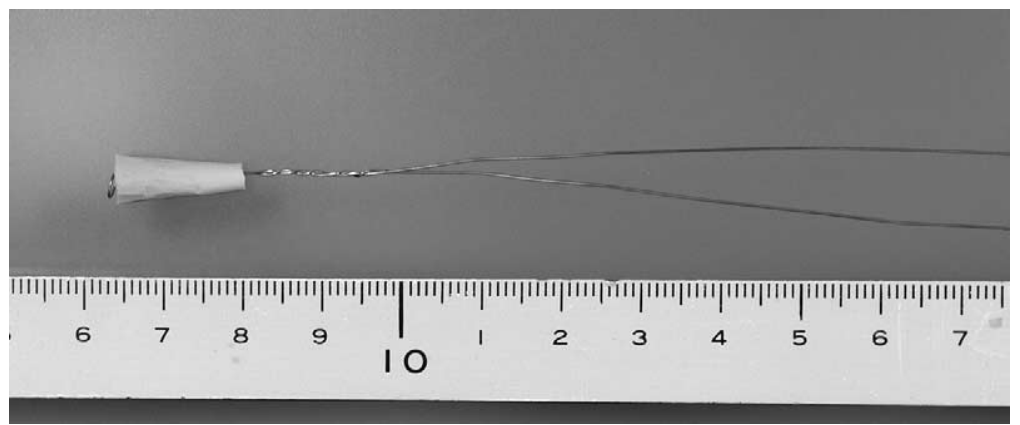

Figure 1. A plug made from polysiloxane impression material with a stainless steel wire.
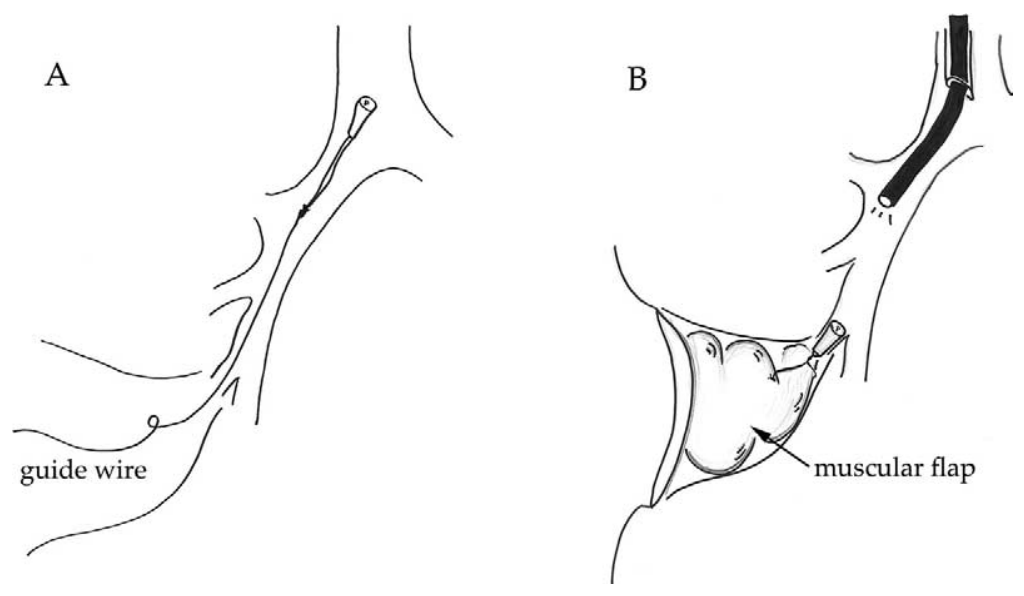

Figure 2. The flap of trapezium muscle was prepared and the edge of the flap was sutured with the plug's wire. Then transposition of the muscle flap was performed.

Watanabe and associates ${ }^{2}$ reported that a patient treated with this plug was followed up without recurrent BPF for 4 years.

We believe this technique is effective in the management of empyema associated with BPF.

\section{References}

1. Regnard JF, Alifano M, Puyo P, Fares E, Magdeleinat P, Levasseur P. Open window thoracostomy followed by intrathoracic flap transposition in the treatment of empyema complicating pulmonary resection. $J$ Thorac Cardiovasc Surg. 2000;120:270-5.
2. Watanabe N, Kanagawa T, Maeta K, Ohishi M, Kodera M, Yamashita Y. A new technique for muscle flap closure of the empyema space in complicated chronic bronchopleural fistula: wedging the causative bronchus with a plug. Jpn J Thorac Cardiovasc Surg. 2002;50:466-71.

3. Puskas JD, Mathisen DJ, Grillo HC, Wain JC, Wright CD, Moncure AC. Treatment strategies for bronchopleural fistula. $J$ Thorac Cardiovasc Surg. 1995;109:989-95; discussion 995-6.

4. Garcia-Yuste M, Ramos G, Duque JL, Heras F, Castanedo M, Cerezal LJ, et al. Open-window thoracostomy and thoracomyoplasty to manage chronic pleural empyema. Ann Thorac Surg. 1998;65: $818-22$. 